\title{
CRUZADA DE EDUCADORAS CATÓLICAS: A MARCHA DAS MULHERES CONTRA O LAICISMO NOS ANOS 30
}

Maria das Graças Andrade Ataíde de Almeida ${ }^{1}$

Resumo: Este trabalho objetiva desconstruir o discurso da imprensa - jornais e revistas- acerca das relações entre educação, poder político e poder religioso em Pernambuco, nas décadas de 30 e 40, no governo Vargas. Procurar-se-á analisar o papel dos leigos junto à Igreja, destacando a atuação da Cruzada de Educadoras Católicas, criada em 1931, com objetivo preciso de fazer barreira através da prática pedagógica, às idéias apontadas como comunistas.

Unitermos: autoritarismo, educação, mulheres, laicato, igreja, Estado

Este ensaio tem como objetivo desconstruir o discurso da imprensa acerca das imbricações entre poder político, poder religioso e educação em Pernambuco, na era Vargas. Para tanto faz-se necessário compreender o papel desempenhado pela Igreja católica a partir da revolução de 30 , quando a Instituição vislumbra a possibilidade de compartilhar o staffpolítico através de seu laicato fiel. A idéia de usar leigos fiéis como representantes de Roma aparece em 1922 com a Encíclica Ubi Arcano Dei, ${ }^{2}$ onde é instituído a Ação Católica em vários paises, inclusive no Brasil. A estratégia desenvolvida pela Igreja se materializa através de um discurso catequético, apontando a solução para a nação em crise: a pregação e doutrinamento dos dogmas católicos.

Este discurso elege o comunismo como bode expiatório, compartilhando assim do discurso do Estado, especialmente

\footnotetext{
${ }^{1}$ Professora do Programa de Mestrado em Administração Rural e Comunicação Rural da Universidade Federal Rural de Pernambuco e do Programa de PósGraduação em -Historia da Universidade Federal de Pernambuco

2 PIO XI. Encíclica UBI ARCANO DEI (1922). Petrópolis: Vozes, 1957
}

Hist. Ensino, Londrina, v. 6, p. 33-46, out. 2000 
após o levante comunista de 1935. Em 1937, quando da instauração do Estado Novo, as relações entre a política educacional e a ideologia autoritária estadonovista podem ser percebidas através do projeto pedagógico proposto pela Interventoria de Pernambuco, que, sabiamente, colocou a educação a serviço do regime autoritário, objetivando o consenso e a legitimação da sociedade para com a nova ordem política instaurada em 10 de novembro de $1937^{3}$.

Para a desconstrução desta produção de discursos utililizarse-á a análise de discurso na perspectiva teórica que trabalha Eni Orlandi, para a qual todo discurso é pleno de sentidos, e cabe ao analista ao se debruçar sobre os textos, remetê-los ao discurso e interpretá-lo através da análise de suas formas de produção, de sua exterioridade, de sua historicidade, de sua relação com o interdiscurso, ou seja a memória ${ }^{4}$. O discurso será desconstruído também à luz da teoria do imaginário social, através das análises de B. Baczko, para o qual:

"o imaginário social torna-se inteligível e comunicável através da produção dos 'discursos' nos quais e pelos quais se efectua a reunião das representações colectivas numa linguagem's

${ }^{3}$ sobre a relação entre educação e o autoritarismo estadonovista em Pernambuco, vide ALMEIDA, M. das Graças A. Ataide. "Estado Novo: projeto político pedagógico e a construção do saber", In Revista Brasileira de História. SP: ANPUH/Humanitas publicações, v. 18, n. 36, 1998, p 137-160

${ }^{4}$ entre as várias obras de Eni Orlandi, destacamos: Interpretação: autoria, leitura e efeitos do trabalho simbólico. Petrópolis:Vozes, 1996; As formas do Silêncio: no movimento dos sentidos. Campinas:SP-UNICAMP,1997; ORLANDI et all. Gestos de Leitura. Campinas: UNICAMP, 1997

${ }^{5}$ BACZKO, B. "Imaginação Social", In Enciclopedia Einaudi. Portugal: Imprensa Nacional/Casa da Moeda, 1985, p.311 


\section{Cruzada de Educadoras Católicas: o antídoto contra a pedagogia laica}

Já em 1931, logo após a Revolução de 30, foi fundada em Pernambuco a Cruzada de Educadoras Católicas, com o objetivo de recristianizar a sociedade através da educação $0^{6}$. A Cruzada deveria atuar junto ao professorado do estado organizando círculos de estudos e debates sobre questões pedagógicas à luz da doutrina católica. Cabia à Cruzada promover também retiros espirituais para as professoras, no sentido de garantir a eficácia do doutrinamento. Os estudos e debates deveriam ser realizados de forma prática, o cerne dos encontros seria destruir a onda de laicismo que segundo as promotoras pretendia avassalar o Brasil e neste Pernambuco.

A agenda temática de um desses encontros de estudos, é relevante para a compreensão do doutrinamento realizado pela Cruzada junto ao corpo docente do Estado. Basicamente acionavam alguns conceitos que tinham como matriz a preservação de valores morais, o papel da família e a necessidade de disciplina:

- Como ensinar catecismo na Escola Nova-Profa. Celina Didier

- As virtudes morais do educador-Profa. Iracema Morais

- A collaboração da familia na obra da educação- Profa. Aureolina Costa

- Concepção da disciplina na Escola Nova-Profa. Hercilia Cunha

- Como cultivar as virtudes morais dos nossos alunos Profa. Maria Teresa Lins de Melo

\footnotetext{
${ }^{6}$ LEONCIO, Pe. Carlos. Religião e Pedagogia. Conferência pronunciada em sessão solene da Cruzada de Educadoras Católicas a 10 de julho de 1932. Recife, 1932.
}

Hist. Ensino, Londrina, v. 6, p. 33-46, out. 2000 
- A coeducação sob o ponto de vista religioso - profa. M. José Miranda'.

Assim, a CEC trabalhava a partir do paradigma pedagógico da Igreja, refutando as possibilidades de abertura advindas com o movimento dos escolanovistas ${ }^{8}$. Na verdade a CEC nada mais fazia do que ocupar o espaço cedido pelo Estado, sob a orientação da Igreja, e lançar as bases de uma caminhada que culminaria com o advento do Estado Novo. Em 1937, o círculo se completou: a CEC era a responsável não só pela idealização do novo programa de ensino religioso instituído em Pernambuco mas, também pela implantação do Projeto PolíticoPedagógico. Os responsáveis pela elaboração e execução, eram portanto os mesmos que atuavam na Cruzada Católica? .

A CEC apesar de funcionar desde 1931, somente foi inaugurada em 10 de julho de 1932, em sessão solene, sob o lema: "Educação Cristã da Mocidade de Pernambuco." O discurso de abertura proferido pelo Padre Carlos Leoncio, salesiano, agridia de imediato o Manifesto dos Pioneiros Escolanovistas, criticando os pedagogos liberais internacionais, e fazendo apologia à pedagogia de São Tomaz de Aquino, Frans De Hovre, e às idéias pedagógicas fascistas de Gentile. A inauguração da CEC pode ser considerado como o primeiro passo, para o pressionamento sistemático junto ao poder político do Estado, na tentativa de "catolizar" o ensino em Pernambuco ${ }^{10}$.

No entanto o Decreto no. 19.941 de 30 de abril de $1931^{11}$, instituído por Francisco Campos, que dispunha sobre a instrução

\footnotetext{
7 A Gazeta, Recife, 3-01-1939, p 1

${ }^{8}$ sobre o movimento da Escola Nova, vide: MONARCHA, Carlos. A Reinvenção da Cidade e da Multidão: dimensões da modernidade brasileira: a escola nova. São Paulo: Cortez, 1989; CURY, C. R. Jamil. Ideologia e Educação Brasileiracatólicos e liberais. São Paulo: Cortez, 1986.

9 A TRIBUNA, Recife, 28.04.1938, p 3

10 LEONCIO, Pe. Carlos. Religião e Pedagogia. Conferência pronunciada em sessão solene da Cruzada de Educadoras Católicas a 10 de julho de 1932. Recife, 1932.

11 Diário Oficial. 06.05.1931. Decreto n. 19.941, 30.04.1931
} 
religiosa nas escolas, insidia em dois artigos que feriam a soberania demandada pela Igreja. Conforme o Art. 30 o ensino religioso só poderia ser ministrado se houvesse no mínimo 20 alunos que se propusessem a recebê-lo. Pelo Art. 110, o governo poderia, por simples aviso do Ministério da Educação e da Saúde suspender o ensino religioso nas escolas oficiais "quando o exigirem os interesses da ordem publica e a disciplina escolar". Percebe-se que o Estado através destas restrições não abre mão do poder que tem de "ordenar". Faz concessão com garantias. Para a Igreja que se arvorava o manancial gerador da ordem politica, econômica e social, o texto da lei era ultrajante ${ }^{12}$.

Para a CEC o ensino religioso facultativo nas escolas era considerado como uma "nesga de luz no meio das trevas". Todavia, discorrendo analiticamente sobre o Decreto no. 19.941 , criticava as autoridades responsáveis pela educação religiosa, acusando-as de displicência, a qual evidenciava o "nível de nossa ideologia pedagógica”. As críticas incidiam principalmente na linguagem empregada pela lei que permitia o ensino religioso sem, entretanto, torná-lo obrigatório, fato que só ocorreria três anos depois:

"ensino religioso, "sem determinar que religião seja, num país que o espiritismo e seitas estrambólicas, americanas [protestantismo] quer ter a honra de ser religião ${ }^{13}$."

Objetivando ampliar seu poder de pressão, a CEC passou a aceitar no seu quadro, a partir de 1934 professores homens, ultrapassando sua proposta inicial de associados que se restringia a atingir, efetivamente o público feminino ${ }^{14}$.Interessante

\footnotetext{
12 sobre as repercussões do Decreto no. 19.941 de 30 de abril de $1931 \mathrm{em}$ relação ao ensino religioso, vide: ROHDEN, Pe. Huberto. O Decreto do Ensino Religioso: ligeiras reflexões sobre o aspecto histórico, jurídico, social e pedagógico da questão. Porto Alegre: Livraria do Globo, 1932, p 7 .

13 LEONCIO, Pe. Carlos. Religião e Pedagogia. Recife:s/editora, 1932, p 37

${ }^{14}$ A TRIBUNA, Recife, 27-01-1934, p 1
} 
observar que, neste mesmo ano, quando a Constituição seria votada, a Igreja acenava com sua conquista máxima: transformar o ensino religioso facultativo em obrigatório, além de compartilhar o poder político, expresso como uma "Collaboração reciproca." ${ }^{15}$

\section{Educação e Fé : a redenção do Brasil contra os bolchevistas}

Após a Intentona Comunista de 1935 em Pernambuco, a Igreja intensificou sua campanha anti-comunista, tentando persuadir a sociedade pernambucana de que os comunistas estavam dominando os cargos públicos e especialmente, os da área da educação, transformando o estado em uma nova Rússia. Seis meses após, as notícias veiculadas pela imprensa nacional sobre a Guerra Civil Espanhola (1936/1939), corroboravam este discurso, alimentando o imaginário político dos anos trinta. A imprensa católica veiculava textos virulentos sobre os revolucionários, reproduzindo fotos de igrejas espanholas invadidas, com seus utensílios sagrados, "profanados pelos ateus comunistas"16. Este discurso que aponta o 'outro' excluído, o inimigo destruidor a ser extirpado, vem de encontro às análises de B. Baczko, acerca do imaginário social construído nas sociedades, em relação a "nós" e os "outros":

"designara identidade colectiva corresponde, do mesmo passo, a delimitar o seu 'território' e as suas relações com o meio ambiente e, designadamente com os 'outros', e corresponde ainda a formar as imagens dos inimigos e dos amigos"17.

\footnotetext{
${ }^{15}$ Esta expressão foi amplamente usada pela Igreja quando da Assembléia Constituinte de 1933, designando as relações que se esperava entre Estado e Igreja.

${ }_{16}$ Merece destaque a Revista MARIA, de publicação mensal, porta-voz da Congregação Mariana de Pernambuco; vide também: CARNEIRO, Maria Luiza Tucci. "La Guerra Civil Española Atraves de Las Revistas Ilustradas Brasileñas: imagens y simbolismo". IN Estudios Interdisciplinares de America Latina y el Caribe, (2),v.2, julio/deciembre de 1991, p 59-50.

17 BACZKO, B. "Imaginação Social", In Enciclopedia Einaudi. op. cit. p309
} 
Assim, a Intentona Comunista inspirou a Igreja, no ano seguinte, a empreender uma campanha fundamentada na imposição de um dos mais marcantes símbolos do catolicismo: a exposição pública do crucifixo em todas as escola do Estado, salvaguardando o imaginário das tradições do catolicismo. Esta prática da Igreja corrobora a relevância do imaginário social ao se utilizar das referências simbólicas - o crucifixo para os católicos- para criar identidades, apontar os indivíduos que pertencem à mesma sociedade, e também definir "de forma mais ou menos precisa os meios inteligíveis das suas relações com ela, com as divisões internas e as instituições sociais." ${ }^{18}$

A Igreja apregoava sob esta ótica, em manchetes bombásticas, que as normalistas de Pernambuco exigiam a recristianização da escola ${ }^{19}$. Na petição das futuras mestras e estas se auto-intitulam mulheres defensoras da Educação e da Pátria, identificamos a mesma linguagem da Cruzada de Educadoras Católicas contra o comunismo, em que as normalistas afirmam que a defesa do patrimônio moral do estado é tarefa das educadoras escolares. Repetindo o discurso veiculado pela imprensa religiosa acerca dos supostos estupros infringidos às mulheres, leigas e religiosas, pelos comunistas no México $^{20}$, as normalistas se posicionavam como defensoras da honra da mulher brasileira, apontada como o "penhor sagrado da inviolabilidade dos nossos lares". Concluem a petição referindo-se ao movimento de novembro de 1935, como uma grande ameaça, similar àquela representada pela invasão holandesa de 1580. Recuperando a epopéia desempenhada pelas mulheres pernambucanas em Tejucupapo, frente ao

\footnotetext{
${ }^{18}$ BACZKO, B. "Imaginação Social", In Enciclopedia Einaudi. op cit, pp 309/310 19 "As Normalistas de Pernambuco Querem a Recristianização das Escolas", A TRIBUNA, Recife, 21.05.1936, p I e 3.

${ }^{20}$ ALMEIDA, M. das Graças A Ataide "Mexico en sangre: la construcción de la imagen del comunista en la prensa brasileña de los años 30." Anais do VIII FIEAIC - Congreso de La Federacion Internacional de Estudios Sobre America Latina y El Caribe. Universidade de Talca: Chile, 1997, no prelo.
}

Hist. Ensino, Londrina, v. 6, p. 33-46, out. 2000 
invasor infiel, o holandês, comparam-no aos comunistas, que também colocavam em perigo a pátria e a família:

"considerando que os inimigos da pátria e da família, infiltrando-se pelas camadas sociaes, derramaram o sangue dos nossos irmãos e ameaçam ainda os fundamentos da soberania nacional, os corações das jovens pernambucanas palpitam sob o mesmo rytmo que activou as heroínas deTejucupapo contra o invasor sanguinário" ${ }^{21}$.

Assim, este discurso aponta para um imaginário social, onde os espaços sociais estão sendo "contaminados" pelo invasor sanguinário, neste momento o comunista, e apela para a tomada de posição das mulheres frente ao novo herege. Retomando Baczko, o imaginário social construído torna-se uma:

"peça efectiva e eficaz do dispositivo da vida colectiva, em especial, do exercício da autoridade e do poder. Ao mesmo tempo, ele torna-se o lugar e o objecto dos conflitos sociais". ${ }^{22}$

Em ofício datado de 20 de maio de 1936, a Igreja justificava ao Secretário do Interior, a importância de afixar o crucifixo nas escolas, ressaltando numa linguagem carregada de simbolismos, que o crucifixo representava a fé e a redenção do Brasili23. Louvava também a atitude de manifestação de civismo das estudantes, apontada como um contraste na conjuntura por que passava Pernambuco:

21 Revista MARIA, Recife, junho/1936, p 146

${ }^{22}$ BACZKO, B. "Imaginação Social", In Enciclopedia Einaudi. op cit, p 310

${ }^{23}$ A TRIBUNA, Recife, 21-05-1936, p 1 
"quando a horda nefasta de mercenarios vis se levanta cheia de ódios propagando idéas que corrompem os costumes, extinguem os dogmas christãos[..] destrõem a familia e aviltam a pátria"24.

Lembramos aqui as reflexões de P. Bourdieu acerca das imbricações entre o discurso religioso e o discurso político, em momentos de crise. Bourdieu ressalta a relevância para o Poder político da instrumentalidade do discurso catequético junto á sociedade civil. ${ }^{25}$

Dois meses antes uma lei salazarista obrigava o uso do crucifixo em todas as escolas portuguesas. O jornal católico A Gazeta, chegou a elogiar a atitude da Camara Corporativa Portuguesa, que estava cuidando de proporcionar um plano de educação, em que não houvesse uma brecha favorável á infiltração das teorias "anárquicas", que estivesse expurgado da obra tida como infernal e criminosa dos agentes da Terceira Internacional e, finalmente que contasse com uma propaganda nacionalista e ordeira, oposta à preparada pelo "bureau da propaganda communista, montado em repartições especiaes da Russia"26. Fica evidenciado neste discurso o recurso ao mito do complô, à expectativa de que a nação poderia ser assaltada pelos comunistas. Lembramos aqui o trabalho de Raoul Girardet acerca do mito do complô político presente em vários momentos de crise nas sociedades. ${ }^{27}$

Em 1939, A Tribuna ressaltava em artigo intitulado " $A$ feliz idéa de um operário", a proposta de o mesmo colocar um crucifixo nas salas do sindicato. O jornal, porta-voz da Cúria Metropolitana de Olinda e Recife, mostrava a relevância da

\footnotetext{
24 Revista MARIA, Recife, junho/1936, p146

25 BOURDIEU, P. A Economia das Trocas Simbólicas. SP:Perspectiva, 1987

26 "O Crucifixo- Symbolo da Fé Christã- purificando e espiritualizando as escolas". IN A GAZETA, Recife, 08.03.1936, p 1

${ }^{27}$ GIRARDET, R. Mitos e mitologias políticas. SP:Companhia das Letras, 1989
} 
imagem do crucifixo nas salas sindicais, onde as questões operárias eram resolvidas, ressaltando que isto era realizado com todo o critério e a justiça, à luz dos ensinamentos da Igreja, apontada como a única detentora dos verdadeiros conceitos sobre a personalidade humana ${ }^{28}$. Utilizando-nos das reflexões de José Murilo de Carvalho sobre o imaginário político, reafirmamos que "símbolos e mitos podem, por seu caráter difuso, por sua leitura codificada, tornar-se elementos poderosos de projeção de interesses, aspirações e medos coletivos" 29.

O discurso da Igreja concentrava-se na idéia da corrupção dos costumes, na destruição da Família e da Pátria pelos comunistas, identificados como mercenários vis. O lema era salvar o Brasil e Pernambuco da avalanche bolchevista. Esta conjuntura política leva a Igreja a intensificar a sua estratégia de interferência no campo educacional, além de intervir na distribuição dos cargos públicos. Diante dos obstáculos à sua preeminência sobre a educação, a sua proposta de intervenção junto às esferas do poder, nos anos 30 , deveria fazer-se através:

- do controle de cargos públicos,

- da interferência na área educacional,

- da criação de Conselhos Regionais ou diocesano

- de um Conselho Geral da Educação por parte das autoridades eclesiásticas.

Caberia a estes Conselhos traçar as diretrizes da educação católica brasileira, além de supervisionar o conteúdo dos livros didáticos. A idéia central era cristianizar os programas do Ministério de Educação. Afirmava-se que esta mudança seria realizada sem se interferir na qualidade. A percepção da

28 CAVALCANTI, Irineu. "Feliz Idéa de Um Operário". IN A TRIBUNA, 26.03.1939, p 1

29 CARVALHO, J. Murilo. A Formação das Almas. SP:Companhia das Letras, 1989, p 11 
importância da legislação como instrumento político era evidente no discurso da Igreja ao lembrar aos legisladores brasileiros que quando estão legislando, estão dando leis para um país católico. Acrescentava-se que o erro dos legisladores de 1889, residira no fato de que a direção das mentes católicas estava nas consciências atéias, laicas e liberais, dando como conseqüência um lamentável dissídio, entre a legislação que surgiu e o povo que a mesma devia servir ${ }^{30}$.

Para isto fazia-se necessário a interferência do laicato católico nos cargos decisórios da política local e nacional e através deste, efetuar-se-iam os ganhos da Constituição de 1934, na área do ensino e do poder político. Esses intelectuais católicos, alguns políticos, deveriam concretizar os objetivos da Igreja junto à sociedade sociedade civil, assumindo a luta contra os " ateus comunistas". Segundo a versão corrente, estes tinham-se tornado desbravadores de um caminho que levaria as novas gerações para o advento do socialismo integral e revolucionário ${ }^{31}$.

Em seu discurso dirigido contra a filosofia da Escola Nova, a Instituição deixa evidenciado seu temor de ver as futuras gerações como não continuadoras "fiéis" dos dogmas romanos. Acusava a pedagogia defendida por Dewey, de ser social radical e responsável por "inocular o germe destruidor" [bolchevista] na formação católica de nosso povo ${ }^{32}$. Para impedir este processo e garantir a formação de futuros políticos católicos, a Igreja assegurava que era necessária a criação de escolas que formassem profissionais católicos, futuros mestres comprometidos com o ideário da pedagogia catequética; enfim, mestres que edificassem em nosso magistério a pedagogia verídica, livre dos erros e unilateralismo das concepções da

\footnotetext{
30 VIANA, Artur Gaspar. "Os Católicos e a Educação". IN A TRIBUNA, 16.02.1935, p1.

${ }^{31}$ Idem, ibdem

32 MENDES, Oscar. "O Liberalismo no Brasil sob o Ponto de Vista Católico". IN A ORDEM, 1932, p36.
}

Hist. Ensino, Londrina, v. 6, p. 33-46, out. 2000 
pedagogia moderna. Não bastava ter o catolicismo na sociedade, era mister uma preeminência maior, que se apresentava na atitude de "catolizar de verdade" os estabelecimentos de educação. A pedagogia catequética vislumbrava as escolas e cursos superiores como verdadeiros centros de formação espiritual, em vez de meras:

"máquinas de fabricar estudantes mal preparados para resistir à propaganda insidiosa dos professores ateus e communistas confessos ou embuçados"33.

Esse receio para com o futuro das gerações foi bem expresso por Oscar Mendes, representante do laicato católico nacional, que ao analisar a Universidade de Coimbra e o Seminário de Olinda, criado pelo bispo Azeredo Coutinho, no início do século $\mathrm{XIX}$, justifica que aquele religioso, por ter sido educado naquela universidade portuguesa, não percebeu que trazia para o Brasil, padres e professores imbuídos de "idéas libertárias e doutrinas falseadas". Segundo Mendes, esses mestres, teriam transformado a maior casa de Educação do Brasil em um "viveiro onde, se alimentaram e criaram forças de difusão as idéas liberais". Interessante a figura de linguagem utilizada: faz-se uma analogia entre o viveiro, local de procriação e crescimento, e os locais destinados à educação. Neste sentido, Mendes ressaltava que a Escola dos Jesuitas, que deveria ter sido "sementeira" de padres obedientes, virtuosos e instruídos, transformou-se em local de irradiação do liberalismo revolucionário ${ }^{34}$. Fazia-se necessário, portanto, não repetir mais esses erros, e isto só seria possível, com a preeminência não só sobre as escolas, mas, também sobre os temas de ensino, legislação e consciências dos que as elaboram.

${ }^{33}$ A TRIBUNA, Recife, 16-01-1935, p 1

${ }^{34}$ MENDES, Oscar. "O Liberalismo no Brasil sob o Ponto de Vista Católico". IN A ORDEM, op. cit. p36. 
Diante de toda esta demanda da Igreja, a implantação do Estado Novo em Pernambuco foi considerado, como o momento propício para barganhar junto ao poder político, o espaço almejado desde 1930. Ẹnquanto instituição secular ela oferecia um paradigma catequético que respondia ao momento de crise em que o Estado autoritário buscava legitimidade. Os cânones de obediência, autoridade, fidelidade e ordem, representavam alguns dos cânones presentes no paradigma político nacionalista do Estado Novo.

Associada ao modelo catequético, a Igreja tinha a seu lado um laicato fiel, representante da elite dominante do Estado, verdadeiros intelectuais orgânicos, que elaboravam e sistematizavam as visões de mundo a serem interiorizadas na sociedade civil. Segundo Antonio Novais Filho, prefeito da cidade de Recife em 1937, estávamos diante de

"um punhado de inteligências cultas que ligada ao verdadeiro espírito do catolicismo, procura recristianizar todo o nosso meio's5.

Assim, a própria Igreja declarava que a organização do laicato trazia para o seio de Roma, neste século, uma "uma força nova e terrível", que mais uma vez a tornaria invencível. A partir de então, uma verdadeira cruzada contra o lacismo seria empreendida no estado.

Concretizava-se em Pernambuco, com a instauração do Estado Novo, o antigo ideal empreendido por D. Sebastião Leme desde $1916^{36}$ : a colaboração recíproca através da aliança entre o espiritual e o temporal, tendo como alvo o monopólio da educação com objetivo claro e preciso de que a mesma garantiria o futuro do catolicismo na sociedade civil, assim como também

${ }^{35}$ NOVAES FILHO, Antonio. "A Vanguarda da Fé Pernambucana", IN A TRIBUNA, 14.07.1934, p1.

${ }^{36}$ LEME, D. Sebastião de Cintra Carta Pastoral a Olinda ( arcebispo de Olinda e Recife), 1916 . Petrópolis: Vozes,1916

Hist. Ensino, Londrina, v. 6, p. 33-46, out. 2000 
uma elite que representaria um staff político fiel às doutrinas de Roma. A Cruzada de Educadoras Católicas representou parte daquele laicato fiel.

As formas de produção deste discurso construído pelo laicato católico, estão voltadas para a extirpação e exclusão das idéias que pudessem representar qualquer ameaça ao status quo da Igreja. Elege como o "outro" ${ }^{37}$ a ser excluído a figura do comunista. É um discurso que aponta a educação e a religião como as barreiras às idéias chamadas "exóticas". Assim, o discurso da Cruzada de Educadoras Católicas trabalhou no sentido de "higienizar" através da recristianização os temas de ensino.

Abstract: This work aims to deconstruct the discourse of the press - newspapers and magazines- concerning the relation between education, political and religious power in Pernambuco, during the thirties and forties decades, in the Vargas government. Which sought to analyse the parte of the laity together with the church, emphasising the parte of the Roman catholic educacionists, created in 1931, with their precise object being to put up barriers through their teaching tecniques, indicating communist ideas.

Keywords: authoritarianism, education, women, laity, church, State.

\footnotetext{
${ }^{37}$ ALMEIDA, M. das Graças A. Ataíde de. "O discurso da lgreja na Era Vargas, no Brasil, construindo o mito do imigrante indesejável: o judeu", In Dicionário Analítico El Espacio en la cultura latinoamericana, 4. Varsóvia: CESLA/ Universidade de Varsóvia, 1998. Vide também sobre a construção da imagem do outro: TODOROV. T. Nós e os outros. RJ:Zahar, 1993
} 